\title{
New Evidence on Breastfeeding and Postpartum Depression: The Importance of Understanding Women's Intentions
}

\author{
Cristina Borra · Maria Iacovou • Almudena Sevilla
}

Published online: 21 August 2014

(c) The Author(s) 2014. This article is published with open access at Springerlink.com

\begin{abstract}
This study aimed to identify the causal effect of breastfeeding on postpartum depression (PPD), using data on mothers from a British survey, the Avon Longitudinal Study of Parents and Children. Multivariate linear and logistic regressions were performed to investigate the effects of breastfeeding on mothers' mental health measured at 8 weeks, 8,21 and 32 months postpartum. The estimated effect of breastfeeding on PPD differed according to whether women had planned to breastfeed their babies, and by whether they had shown signs of depression during pregnancy. For mothers who were not depressed during pregnancy, the lowest risk of PPD was found among women who had planned to breastfeed, and who had actually breastfed their babies, while the highest risk was found among women who had planned to breastfeed and had not gone on to breastfeed. We conclude that the effect of breastfeeding on maternal depression is extremely heterogeneous, being mediated both by breastfeeding intentions during pregnancy and by mothers' mental health during pregnancy. Our results
\end{abstract}

C. Borra $(\square)$

Facultad de Ciencias Económicas y Empresariales, University of Seville, Ramón y Cajal 1, 41018 Seville, Spain

e-mail: cborra@us.es

\section{Iacovou}

Department of Sociology, University of Cambridge, Free School Lane, Cambridge CB2 3RQ, UK

e-mail: mi305@cam.ac.uk

M. Iacovou

ISER, University of Essex, Colchester CO4 3SQ, UK

\section{A. Sevilla}

Queen Mary University of London, Mile End Road,

London E1 4NS, UK

e-mail: a.sevilla@qmul.ac.uk underline the importance of providing expert breastfeeding support to women who want to breastfeed; but also, of providing compassionate support for women who had intended to breastfeed, but who find themselves unable to.

Keywords Breastfeeding - Mental health - Edinburgh postnatal depression scale $\cdot$ Child development $\cdot$ ALSPAC

\section{Introduction}

Approximately $13 \%$ of women experience postpartum depression (PPD) within the 14 weeks after giving birth [1]. If the antenatal period is also considered, as many as $19 \%$ of women experience a depressive episode during pregnancy or the first 3 months postpartum [2]. Post-natal depression has an immediate impact on mothers and carries long-term risks for mothers' future mental health [3, 4]; it also has significant negative effects on the cognitive, social and physical development of their children [5, 6]. In addition, post-natal depression involves substantial economic costs, in terms of costs to healthcare systems [7] and losses in productivity via maternal absenteeism from work, premature retirement, and long-term unemployment [8].

The effect of breastfeeding on the risk of PPD is not well understood. Several studies have demonstrated an association between longer breastfeeding durations and a lower prevalence of PPD [9-14]. However, other studies have suggested the opposite, namely that breastfeeding mothers are at increased risk of PPD [15, 16]; or found no association $[17,18]$. Of those studies which suggest beneficial effects from breastfeeding, several have relied on small samples, and few have controlled for potential confounders such as socioeconomic factors (maternal education, family income, marital status), the quality of relationships (marital 
stability, social networks), and stressful life events [19, 20]. Thus, it has been extremely difficult to identify whether the observed relationships are causal, as opposed to arising because breastfeeding is more likely to be practiced by mothers whose characteristics are themselves associated with a lower risk of depression [21-23]. Additionally, as Ip et al. [24] have pointed out, most existing studies have not controlled for pre-existing mental health conditions.

Thus, the extent to which breastfeeding influences mental health, as opposed to mental health driving the incidence and duration of breastfeeding, has not been clear. The aim of the current study is to examine explicitly whether breastfeeding affects maternal mental health outcomes. Specifically, we examine the hypothesis that the relationship between breastfeeding and maternal mental health is mediated by the mother's intention to breastfeed. The relationship between breastfeeding and maternal mental health may be driven by biological factors, such as differences in hormone levels between breast- and formulafeeding mothers [25]; if maternal mental health is also affected by mothers' feelings of success or failure in relation to their original plans and aspirations, we may expect the intention to breastfeed to play a crucial role.

\section{Data and Methods}

\section{Data and Key Variables}

This research is based on data from the Avon Longitudinal Survey of Parents and Children (ALSPAC), a survey of around 14,000 children born in the Bristol area of England in the early 1990s [26]. Mothers were recruited into the survey by doctors, at the point when they first reported their pregnancy. Data were collected by questionnaires administered to both parents at four points during pregnancy and at several stages following birth.

Details of all data collected in the ALSPAC survey are available on the study website through a fully searchable data dictionary [27]. Our study obtained ethical approval from the ALSPAC Law and Ethics Committee and the Local Research Ethics Committees.

We used a sample of mothers whose children form the "core sample" of ALSPAC. This sample consists of 14,541 pregnancies which resulted in 14,676 known foetuses; there were 14,062 live births, and 13,988 babies surviving to 1 year. We employed a maximizing strategy with respect to sample size, using as many observations as possible to analyse each outcome-effect dyad. Sample sizes thus vary slightly between regressions. The experiences of mothers and babies following pre-term births, or separation due to NICU care, may differ from the experiences of other mothers and babies. We do not exclude these mother/baby pairs from our sample, but have checked that our results do not change if they are excluded; these results are available from the authors on request.

As a measure of depression, the Edinburgh Postnatal Depression Scale (EPDS) was used. The EPDS, designed by Cox et al. [28] to screen for PPD, was collected during pregnancy at 18 and 32 weeks' gestation, and post-natally at 8 weeks, and 8, 18, and 33 months. The EPDS is the most frequently used screening questionnaire for PPD; the EPDS is sensitive to changes in depression over time, and has been demonstrated to be a valid and reliable tool for the measurement of both postpartum and antenatal depression $[29,30]$. The instrument consists of 10 questions, each with four possible answers describing symptoms of increasing severity or duration; aggregate scores on the EPDS range from 0 to 30. The authors of the EPDS have suggested that women should be referred to a mental health specialist if they score 13 or higher during the post-partum period [31] and 15 or more during pregnancy [32]. Therefore, we constructed indicators of depressive symptomatology, defined as EPDS $>14$ in pre-natal assessments and EPDS $>12$ in postpartum assessments.

Mothers were asked during pregnancy how they intended to feed their babies for the first 4 weeks. Following their child's birth, they were asked at several points how they were actually feeding, and the ages at which infant formula and solid foods were introduced. Using this information, we computed seven binary indicators: (1) initiation (putting the baby to the breast at least once); (2-4) any breastfeeding for at least 1,2 and 4 weeks respectively; and (5-7) exclusive breastfeeding for at least 1,2 and 4 weeks respectively. We also computed two continuous indicators: total duration of breastfeeding and total duration of exclusive breastfeeding; results for these continuous indicators are similar to results obtained using the binary indicators, and are available from the authors on request.

\section{Analysis}

We estimate multivariate logistic regressions, presenting odds ratios and $95 \%$ confidence intervals. All hypotheses are tested using two-tailed $p$ values $<0.05$.

We present estimates from three specifications. Model A controls only for the child's sex and parental education. Model B additionally controls for other socio-demographic variables, and information on pregnancy and birth. Finally, Model C includes information on the mother's physical and mental health, including antenatal EPDS assessments, together with factors relating to the quality of interpersonal relationships and stressful life events (see Table 6 in the Appendix for precise definitions of these variables). Thus, Model A provides a first approximation to the associations of interest, Model B estimates these relationships net of a range of potential confounders, while Model C aims to estimate 
Table 1 Descriptive statistics for variables of interest

\begin{tabular}{|c|c|c|c|}
\hline & $\mathrm{N}$ & mean & s.d. \\
\hline \multicolumn{4}{|l|}{ Maternal mental health during pregnancy } \\
\hline $\begin{array}{l}\text { At risk of antenatal depression, } 18 \text { weeks } \\
\quad(\text { EPDS }>14)\end{array}$ & 10,904 & $7 \%$ & $(0.3)$ \\
\hline $\begin{array}{l}\text { At risk of antenatal depression, } 32 \text { weeks } \\
\text { (EPDS }>14)\end{array}$ & 11,305 & $8 \%$ & $(0.3)$ \\
\hline \multicolumn{4}{|l|}{ Maternal mental health post-partum } \\
\hline $\begin{array}{l}\text { At risk of postpartum depression, } 8 \text { weeks } \\
(\text { EPDS }>12)\end{array}$ & 10,756 & $10 \%$ & $(0.3)$ \\
\hline $\begin{array}{l}\text { At risk of postpartum depression, } 8 \text { months } \\
(\text { EPDS }>12)\end{array}$ & 10,345 & $8 \%$ & $(0.3$ \\
\hline $\begin{array}{l}\text { At risk of postpartum depression, } \\
21 \text { months (EPDS }>12)\end{array}$ & 9,605 & $10 \%$ & $(0.3)$ \\
\hline $\begin{array}{l}\text { At risk of postpartum depression, } \\
33 \text { months (EPDS }>12 \text { ) }\end{array}$ & 8,985 & $12 \%$ & $(0.3$ \\
\hline \multicolumn{4}{|l|}{ Breastfeeding } \\
\hline Mother intended to breastfeed & 11,547 & $65 \%$ & $(0.5)$ \\
\hline Initiated breastfeeding & 11,012 & $80 \%$ & $(0.4)$ \\
\hline Breastfed for 1 week & 10,668 & $74 \%$ & $(0.4)$ \\
\hline Breastfed for 2 weeks & 10,680 & $68 \%$ & $(0.5)$ \\
\hline Breastfed for 4 weeks & 10,972 & $56 \%$ & $(0.5)$ \\
\hline Duration of any breastfeeding (months) & 8,317 & 5.17 & $(4.7)$ \\
\hline Exclusively breastfed for 1 week & 10,668 & $64 \%$ & $(0.5)$ \\
\hline Exclusively breastfed for 2 weeks & 10,680 & $60 \%$ & $(0.5)$ \\
\hline Exclusively breastfed for 4 weeks & 10,972 & $43 \%$ & $(0.5)$ \\
\hline $\begin{array}{l}\text { Duration of exclusive breastfeeding } \\
\text { (months) }\end{array}$ & 8,726 & 1.31 & $(1.2$ \\
\hline
\end{tabular}

Figures in the middle column are means in the case of continuous variables, and percentages of the sample in the case of dichotomous variables

causal relationships as accurately as possible by eliminating potential reverse causality arising from the fact that previously depression-prone mothers may be less likely to decide to breastfeed, or to breastfeed for shorter durations.

After conducting this analysis for the whole sample, we split the sample into mothers who were, and who were not, depressed during pregnancy; for each group, we examine differences in outcomes between women who had planned to breastfeed, and women who had not.

\section{Results}

\section{Study Variables}

Descriptive statistics for variables of interest are shown in Table 1. The prevalence of antenatal depression, using a cut-off of EPDS $>14$, is $7 \%$ at 18 weeks' pregnancy and $8 \%$ at 32 weeks, similar to rates reported in previous studies [33]. Rates of PPD were between 9 and $12 \%$, also similar to results from former analyses [34].
$80 \%$ of mothers in this sample initiated breastfeeding and $74 \%$ breastfed for 1 week or more. By 4 weeks only $56 \%$ of mothers were breastfeeding at all and only $43 \%$ were breastfeeding exclusively. The percentages of women feeding for the different durations considered are shown in Table 1; mean durations for breastfeeding and exclusive breastfeeding are also shown.

Table 2 shows the raw relationships between postnatal depressive symptomatology, and (a) prenatal depression, and (b) different measures of breastfeeding duration. A significant degree of correlation is present between postnatal and antenatal EPDS scores; a clear negative relationship also exists between symptoms of maternal depression measured at 8 weeks, and breastfeeding duration. The association between depression and breastfeeding is always negative, but generally statistically insignificant, at 8,21 and 33 months.

\section{Sample Characteristics}

Socio-demographic characteristics for sample members are presented in Table 7 in the Appendix. The mean age of participants was 28.3 years $(\mathrm{SD}=4.8) .95 \%$ of the women were white, $86 \%$ were married, $13 \%$ had university degrees, while a further $22 \%$ had high school qualifications at age 18 ("A" levels); and $74 \%$ owned the house in which they lived. In relation to pregnancy and birth, $64 \%$ felt usually well, $55 \%$ percent were working while pregnant, $45 \%$ were primiparous, and only $9 \%$ delivered via Cesarean section. The average gestational age was 39.5 weeks $(\mathrm{SD}=1.8) .48 \%$ of mothers and $37 \%$ of fathers had themselves been breastfed as babies. $28 \%$ of the pregnancies were unplanned; $15 \%$ of mothers had lived through their own parents' divorce before their eighteenth birthday.

Table 3 presents the results of logistic regressions estimating the effect of breastfeeding on PPD.

As explained earlier, three models are estimated: Model A controls only for the child's sex and parental education; Model B controls in addition for a wide range of socioeconomic and demographic factors, plus information on pregnancy and birth; and Model $\mathrm{C}$ also controls for mother's health (including mental health) in pregnancy, relationship quality and stressful life events.

We consider four different outcomes: EPDS $>12$ measured at 8 weeks, 8,21 and 33 months postpartum. For each model/outcome dyad, the model is estimated seven times, for seven different measures of breastfeeding (initiation; any breastfeeding for at least 1,2 and 4 weeks; and exclusive breastfeeding for at least 1,2 and 4 weeks). Thus, each coefficient in Table 3 comes from a separate regression.

At 8 weeks postpartum, we observe a pronounced relationship between breastfeeding and PPD, under both 
Table 2 Raw correlations between study variables

\begin{tabular}{|c|c|c|c|c|}
\hline & \multicolumn{4}{|c|}{ Postpartum EPDS scores } \\
\hline & $\begin{array}{l}\text { Postnatal EPDS }>12 \\
\text { at } 8 \text { weeks }\end{array}$ & $\begin{array}{l}\text { Postnatal EPDS }>12 \\
\text { at } 8 \text { months }\end{array}$ & $\begin{array}{l}\text { Postnatal EPDS }>12 \\
\text { at } 21 \text { months }\end{array}$ & $\begin{array}{l}\text { Postnatal EPDS }>12 \\
\text { at } 33 \text { months }\end{array}$ \\
\hline \multicolumn{5}{|l|}{ Maternal mental health during pregnancy } \\
\hline Antenatal EPDS $>14$ at 18 weeks & $0.279 * * *$ & $0.220 * * *$ & $0.216 * * *$ & $0.207 * * *$ \\
\hline Antenatal EPDS $>14$ at 32 weeks & $0.350 * * *$ & $0.309 * * *$ & $0.288 * * *$ & $0.271 * * *$ \\
\hline \multicolumn{5}{|l|}{ Breastfeeding measures } \\
\hline Initiated breastfeeding & $-0.034 * *$ & $-0.027 *$ & -0.018 & -0.018 \\
\hline Breastfed for 1 week or more & $-0.037 * *$ & -0.021 & -0.019 & -0.015 \\
\hline Breastfed for 2 weeks or more & $-0.038 * *$ & -0.023 & -0.015 & -0.010 \\
\hline Breastfed for 4 weeks or more & $-0.037 * *$ & -0.011 & -0.005 & -0.005 \\
\hline Duration of any breastfeeding & $-0.044 * * *$ & -0.021 & -0.020 & -0.009 \\
\hline Exclusively breastfed for 1 week or more & $-0.041 * * *$ & -0.019 & -0.023 & -0.022 \\
\hline Exclusively breastfed for 2 weeks or more & $-0.040 * * *$ & $-0.033 * *$ & -0.018 & $-0.026^{*}$ \\
\hline Exclusively breastfed for 4 weeks or more & $-0.052 * * *$ & -0.021 & -0.016 & -0.013 \\
\hline Duration of exclusive breastfeeding & $-0.036^{* *}$ & -0.025 & -0.021 & -0.014 \\
\hline
\end{tabular}

$P$ values are indicated by asterisks, with $* P<0.05$, ** $P<0.01$, *** $P<0.001$

Models A and B. The odds ratios for these models indicate that longer durations of breastfeeding are associated with larger reductions in the risk of PPD, and exclusive breastfeeding is associated with a larger reduction than any breastfeeding. However, under Model C, when we control for mothers' health during pregnancy, these effects largely disappear; the only significant relationship which remains comes from exclusive breastfeeding for 4 weeks or longer (OR 0.81, $95 \%$ CI 0.68, 0.97).

The relationship between breastfeeding and PPD is also weaker, the later the EPDS score is assessed; at 8 months postpartum and thereafter, most of the estimated coefficients are not significantly different from zero (indeed, a few of the results are counter-intuitive, suggesting that breastfeeding may be positively related to an increased risk of depression measured at 33 months postpartum).

Thus, for the sample as a whole, our results demonstrate little evidence for a causal relationship between breastfeeding and the risk of PPD. In the next section, we investigate the possibility that the relationship between breastfeeding and depression varies according to two factors: whether mothers were assessed as at risk of depression during pregnancy, and whether they had been planning to breastfeed their babies. We show that the relationship between breastfeeding and depression is indeed highly heterogeneous, and that this fact explains why little effect is found when considering women as a homogeneous group.

Heterogeneous Effects by Mental Health During Pregnancy and Breastfeeding Intention

We re-estimated Model C separately for mothers who were, and who were not, depressed during pregnancy (in terms of having a score EPDS $>14$ at least once during pregnancy). As before, we estimated regressions separately for each time at which postnatal depression was assessed ( 8 weeks, and 8, 21 and 33 months postpartum); for each of these time periods, we estimated seven models, one for each discrete measure of breastfeeding. However, instead of simply controlling for whether or not mothers breastfed for the relevant duration, we identify four groups of women, by whether they had planned to breastfeed, and whether they had actually breastfed for the relevant duration. These four groups are:

- Mothers who had not planned to breastfeed, and who did not breastfeed (reference group)

- Mothers who had not planned to breastfeed, but who did actually breastfeed

- Mothers who had planned to breastfeed, but who did not actually breastfeed

- Mothers who had planned to breastfeed, and who did actually breastfeed

Each regression thus generates three coefficients of interest; these coefficients are expressed as odds ratios, relative to the reference group.

Table 4 presents results for mothers without prenatal depression symptoms. Column (2) displays odds ratios and confidence intervals for mothers who did not plan to breastfeed, but who did actually breastfeed; column (3) indicates whether these mothers are significantly different from the mothers in the reference group.

Column (4) presents odds ratios for mothers who planned to breastfeed but who did not breastfeed for the relevant duration; Column (5) present odds ratios for mothers who 
Table 3 Results from logistic regressions: effects of breastfeeding on postpartum depression

\begin{tabular}{|c|c|c|c|}
\hline & $\begin{array}{l}\text { Model A } \\
\text { Adjusted OR } \\
{[95 \% \mathrm{CI}]}\end{array}$ & $\begin{array}{l}\text { Model B } \\
\text { Adjusted OR } \\
{[95 \% \mathrm{CI}]}\end{array}$ & $\begin{array}{l}\text { Model C } \\
\text { Adjusted OR } \\
{[95 \% \text { CI }]}\end{array}$ \\
\hline \multicolumn{4}{|c|}{ Dependent variable: EPDS $>12$ at 8 weeks } \\
\hline Breastfeeding initiated & $0.87[0.74,1.03]$ & $1.06[0.88,1.27]$ & $1.1[0.89,1.37]$ \\
\hline Any b/f, 1 week + & $0.8[0.69,0.93]^{* *}$ & $0.95[0.80,1.13]$ & $1.08[0.88,1.33]$ \\
\hline Any b/f, 2 weeks + & $0.83[0.71,0.96]^{*}$ & $0.93[0.78,1.09]$ & $0.98[0.81,1.19]$ \\
\hline Any b/f, 4 weeks + & $0.77[0.67,0.89]^{* * *}$ & $0.81[0.70,0.95]^{* *}$ & $0.88[0.74,1.06]$ \\
\hline Exclusive b/f, 1 week + & $0.8[0.70,0.92]^{* *}$ & $0.91[0.78,1.06]$ & $0.99[0.82,1.19]$ \\
\hline Exclusive b/f, 2 weeks + & $0.78[0.68,0.90]^{* * *}$ & $0.85[0.73,0.99]^{*}$ & $0.89[0.74,1.06]$ \\
\hline Exclusive b/f, 4 weeks + & $0.73[0.64,0.85]^{* * *}$ & $0.75[0.64,0.88]^{* * *}$ & $0.81[0.68,0.97]^{*}$ \\
\hline $\mathrm{N}$ & $10,509-10,546$ & $10,393-10,428$ & $9,722-9,757$ \\
\hline \multicolumn{4}{|c|}{ Dependent variable: EPDS $>12$ at 8 months } \\
\hline Breastfeeding initiated & $0.86[0.72,1.03]$ & $1.01[0.83,1.23]$ & $0.99[0.79,1.24]$ \\
\hline Any b/f, 1 week + & $0.9[0.76,1.07]$ & $1.04[0.86,1.25]$ & $1.15[0.93,1.43]$ \\
\hline Any b/f, 2 weeks + & $0.88[0.75,1.03]$ & $0.98[0.82,1.17]$ & $1.02[0.84,1.25]$ \\
\hline Any b/f, 4 weeks + & $0.89[0.76,1.04]$ & $0.95[0.81,1.13]$ & $1.05[0.87,1.28]$ \\
\hline Exclusive b/f, 1 week + & $0.92[0.79,1.07]$ & $1.02[0.86,1.21]$ & $1.12[0.92,1.36]$ \\
\hline Exclusive b/f, 2 weeks + & $0.83[0.71,0.97]^{*}$ & $0.9[0.76,1.06]$ & $0.93[0.77,1.12]$ \\
\hline Exclusive b/f, 4 weeks + & $0.86[0.74,1.00]$ & $0.9[0.76,1.06]$ & $1.02[0.84,1.23]$ \\
\hline $\mathrm{N}$ & $10,080-10,116$ & $9,258-9,999$ & $9,354-9,388$ \\
\hline \multicolumn{4}{|c|}{ Dependent variable: EPDS $>12$ at 21 months } \\
\hline Breastfeeding initiated & $0.93[0.78,1.11]$ & $1.08[0.89,1.32]$ & $1.09[0.87,1.37]$ \\
\hline Any b/f, 1 week + & $0.97[0.82,1.15]$ & $1.14[0.94,1.38]$ & $1.26[1.02,1.56]^{*}$ \\
\hline Any b/f, 2 weeks + & $1[0.86,1.18]$ & $1.11[0.93,1.33]$ & $1.19[0.97,1.46]$ \\
\hline Any b/f, 4 weeks + & $0.99[0.85,1.14]$ & $1.03[0.87,1.21]$ & $1.15[0.95,1.38]$ \\
\hline Exclusive b/f, 1 week + & $0.93[0.80,1.08]$ & $1.04[0.88,1.23]$ & $1.19[0.98,1.44]$ \\
\hline Exclusive b/f, 2 weeks + & $0.96[0.82,1.11]$ & $1.03[0.87,1.21]$ & $1.11[0.92,1.33]$ \\
\hline Exclusive b/f, 4 weeks + & $0.9[0.77,1.04]$ & $0.92[0.79,1.08]$ & $1.06[0.88,1.27]$ \\
\hline $\mathrm{N}$ & $9,370-9,406$ & $9,258-9,929$ & $8,704-8,737$ \\
\hline \multicolumn{4}{|c|}{ Dependent variable: EPDS $>12$ at 33 months } \\
\hline Breastfeeding initiated & $1.04[0.88,1.24]$ & $1.22[1.01,1.48]^{*}$ & $1.22[0.98,1.51]$ \\
\hline Any b/f, 1 week + & $1.01[0.86,1.18]$ & $1.16[0.97,1.39]$ & $1.27[1.04,1.55]^{*}$ \\
\hline Any b/f, 2 weeks + & $1.02[0.87,1.18]$ & $1.13[0.95,1.33]$ & $1.19[0.99,1.44]$ \\
\hline Any b/f, 4 weeks + & $1.01[0.88,1.16]$ & $1.07[0.92,1.25]$ & $1.17[0.98,1.39]$ \\
\hline Exclusive b/f, 1 week + & $0.92[0.80,1.06]$ & $1.01[0.86,1.18]$ & $1.09[0.92,1.30]$ \\
\hline Exclusive b/f, 2 weeks + & $0.9[0.78,1.03]$ & $0.96[0.82,1.11]$ & $0.99[0.84,1.18]$ \\
\hline Exclusive b/f, 4 weeks + & $0.95[0.83,1.09]$ & $0.98[0.85,1.14]$ & $1.1[0.93,1.29]$ \\
\hline $\mathrm{N}$ & $8,704-8,805$ & $8,676-8,706$ & $8,172-8,202$ \\
\hline
\end{tabular}

Coefficients are expressed as odds ratios and $95 \%$ confidence intervals. Each estimated coefficient comes from a different regression. Model A controls for the child's sex and parental education. Model B additionally controls for pregnancy and birth information; child characteristics at birth; demographic and socio-economic variables; and breastfeeding attitudes. Model C also controls for mother's health in pregnancy, interpersonal relationships, and stressful life events (see Table 6 in the Appendix). Sample sizes vary slightly between regressions; the range of $\mathrm{N}$ is given in each panel

$P$ values are indicated by asterisks, with $* P<0.05$, ** $P<0.01$, *** $P<0.001$

planned to breastfeed, and who did breastfeed for the relevant duration. Column (6) indicates whether the odds ratios in Column (4) and (5) are significantly different from each other. Thus, the test results in Column (3) indicate whether breastfeeding makes a difference in the case of women who did not originally plan to breastfeed, while the tests in Column (6) indicate whether breastfeeding makes a difference in the case of mothers who had planned to breastfeed.

The strongest result from Table 4 is that breastfeeding is strongly associated with a lower risk of depression at 


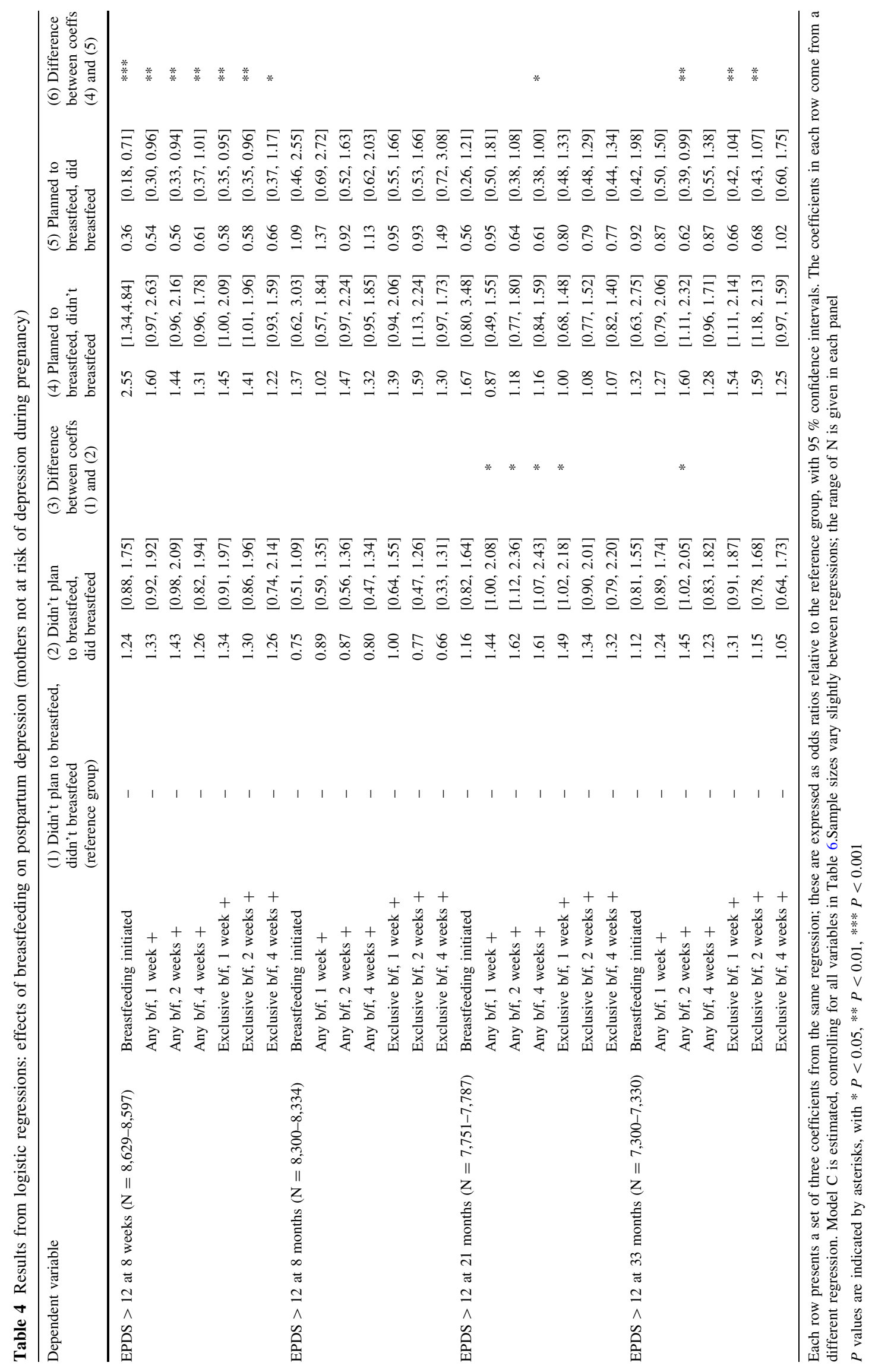


8 weeks postpartum, for women who had planned to breastfeed. The odds ratios in Column 4 are all well over 1, while the odds ratios in Column 5 are all well below 1; the differences between the two are statistically significant at the $1 \%$ level or better for the first six measures of breastfeeding, and significant at the $5 \%$ level for the remaining measure. The effects are smaller for later assessment periods. At 8 and 21 months, the odds ratios in Column 5 are lower than the odds ratios in Column 4 in almost all cases; however, the differences are not statistically significant. At 33 months, the differences are larger again, and are significant at the $1 \%$ level for three of the seven measures of breastfeeding.

Interestingly, among the group of mothers who had not planned to breastfeed, the risk of depression was higher among women who went on to breastfeed. These differences are statistically significant for depression measured at 21 months, the largest being for any breastfeeding for 2 weeks on EPDS at 21 months (OR 1.62; $95 \%$ CI 1.12, 2.36); at 8 weeks and 33 months the coefficients are all positive, though not generally significant at the $5 \%$ level). To test whether our results were driven by a few mothers with very severe depressive symptoms, we repeated the analysis excluding those mothers with EPDS scores of 20 or more (the cut-off used in general practitioners' guidelines [35] ); the results were virtually the same. We also investigated whether the effects depended on whether the mother was primiparous or multiparous, as suggested by [36]; again, the results were not affected.

Results for mothers who had been assessed as at risk of depression during pregnancy are shown in Table 5. For this group, results are less well defined, at least in part because of the smaller sample size. Our findings suggest that among women who had planned to breastfeed, breastfeeding is associated with a lower risk of PPD (as for mothers not depressed during pregnancy, although with a much smaller effect). However, for previously depressed mothers, there may also be a protective effect from breastfeeding when mothers had not planned to breastfeed. These results should be interpreted with caution: the only significant effect was found on EPDS measured at 8 weeks and for at least 4 weeks' exclusive breastfeeding (OR 0.42; $95 \%$ CI 0.20, 0.90).

\section{Discussion}

The aim of this study was to examine whether breastfeeding influenced the risks of postnatal depression. This study extends previous research by using a large longitudinal dataset; controlling for a large set of socioeconomic, relational, and psychosocial confounders; measuring maternal mood at different time points both before and after delivery; and utilising several measures of breastfeeding initiation, duration, and exclusivity.
We found that the effect of breastfeeding on maternal mood differed by both maternal mental health during pregnancy; and whether mothers intended to breastfeed. To our knowledge, this study is the first to document this result.

For the majority of mothers who did not show symptoms of depression before birth, breastfeeding decreased the risk of PPD among mothers who had intended to breastfeed, but increased the risk of PPD among mothers who had not intended to breastfeed.

We also found that the beneficial effects of breastfeeding were strongest at 8 weeks after birth, and that the association was weaker at 8 months and onwards. This finding is in line with the findings of the only other longitudinal research in this area [37] which significant effects at 6 weeks but not at 12 weeks postpartum. Our results are nevertheless important, because of the established relationship between depression, even in the very early postpartum period, and maternal-infant bonding [38].

Estimates for the smaller group of mothers who had shown signs of depression during pregnancy were less precise, but differed from the estimates for non-depressed women in two important ways. The protective effects of breastfeeding as planned were smaller for women who had been depressed during pregnancy; but exclusive breastfeeding for 4 weeks appeared to exercise a protective effect for this group, which it did not do for the women who had not been depressed in pregnancy.

We recognize several limitations in our analyses. Although we employ the most commonly used measure of depressive symptomatology, we acknowledge that including a clinical diagnosis of antenatal and PPD would have increased the value of our findings. Also, misclassification bias may arise when relying on self-report methods to assess breastfeeding outcomes. Thirdly, even though we use a large population-based sample with low loss to follow-up, sampling bias resulting from the voluntary nature of participation in the survey could have influenced results. For instance, we acknowledge a shortfall in the numbers of ethnic minority mothers that may limit the generalizability of the results. Finally, even though we control for many more potential confounders than any other study on the subject, there may remain some unobserved factor, for example aspects of maternal IQ or personality, which could affect the results.

In summary, the effect of breastfeeding on maternal depression symptoms was found to be highly heterogeneous and, crucially, mediated by breastfeeding intentions during pregnancy. Our most important finding relates to the majority of mothers who were not depressed during pregnancy, and who planned to breastfeed their babies. For these mothers, breastfeeding as planned decreased the risks of PPD, while not being able to breastfeed as planned increased the risks. These findings have implications for 


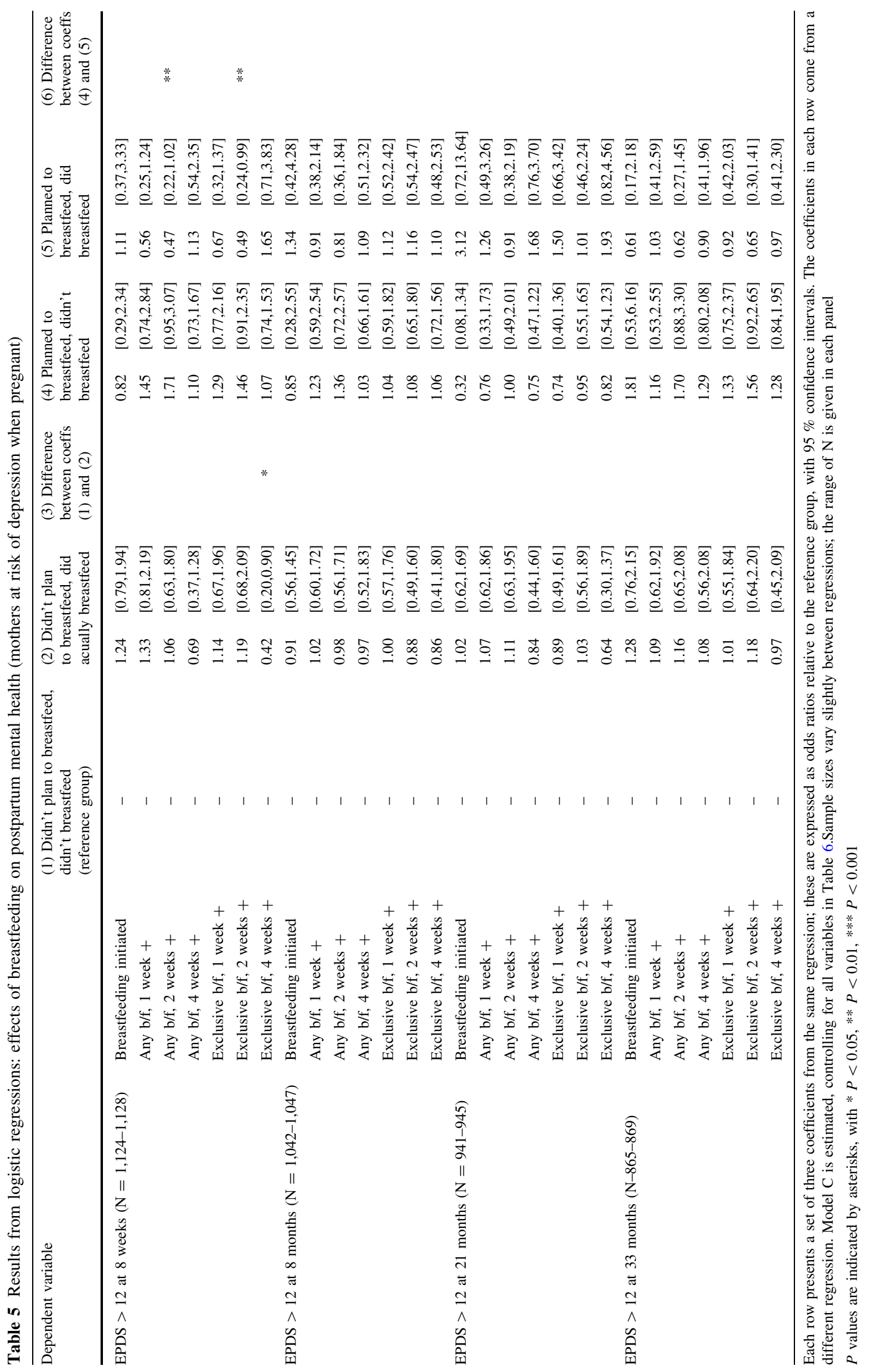


the way in which new mothers are supported; they suggest that the provision of expert breastfeeding support may, in addition to increasing breastfeeding rates and durations, have the additional benefit of improving mental health outcomes among new mothers. At the same time, it is clear that where mothers had intended to breastfeed, not being able to breastfeed may have deleterious consequences on their risk of PPD, and that providing specialised support to new mothers who had intended to breastfeed, but who for some reason find themselves unable to breastfeed, may also constitute a desirable health policy objective.

Acknowledgments This paper has benefited from comments provided by participants at the 20th Public Economics Meeting and at the 27th Annual Conference of the European Society for Population Economics. We acknowledge comments and support from colleagues at ISER, particularly Emilia del Bono and Birgitta Rabe. We are extremely grateful to all the families who took part in this study, the midwives for their help in recruiting them, and the whole ALSPAC team, which includes interviewers, computer and laboratory technicians, clerical workers, research scientists, volunteers, managers, receptionists and nurses. The UK Medical Research Council and the Wellcome Trust (Grant ref: 092731) and the University of Bristol provide core support for ALSPAC. This publication is the work of the authors, who will all serve as guarantors for the contents of this paper. This research was specifically funded by the UK's Economic and Social Research Council (ESRC) under research Grant RES-062-231693 Effects of breastfeeding on children, mothers and employers. The authors are independent from the ESRC.

Open Access This article is distributed under the terms of the Creative Commons Attribution License which permits any use, distribution, and reproduction in any medium, provided the original author(s) and the source are credited.

\section{Appendix 1}

See Table 6.

Table 6 List of variables used in the analysis

Socio-demographic variables (at or during pregnancy)

Two dummies for housing tenure which take the value 1 if the mother owned the house or rented the house during pregnancy (omitted category is social housing); the number of rooms in the house during pregnancy; neighborhood indicators with higher values indicating a better neighbourhood; a dummy indicating the mother's race (white, with omitted category nonwhite); three dummies indicating the marital status of the mother at the time of pregnancy (married, cohabiting, single/ separated/divorced); five dummies indicating the mother's and father's education level (university degree; A levels (school qualifications obtained at age 18); O levels (school qualifications obtained at age 16); CSE (a lower level of school qualifications obtained at age 16) and vocational); and an indicator variable that takes the value 1 if the mother was working at 18 weeks of pregnancy.
Table 6 continued

Pregnancy and delivery information

A dummy that takes value 1 if the child is a female; a dummy that takes value 1 if the child is a twin; mother's age at birth; an indicator variable that takes value 1 if the mother had a cesarean section; the length of the gestation period.

Health variables

Dummy variables for different physical health levels; number of cigarettes smoked each day measured at 32 weeks of pregnancy; number of alcoholic beverages a day before pregnancy; and antenatal EPDS measured at 18 and 33 months pregnancy.

Interpersonal relationships, personality, and stressful life events

Dragona's et al. (1992) measure of the mother's social network availability; Quinton and Rutter's (1988) aggression and affection scores for marital quality; a psychological measure of the mother's personality: the adult version of the NowickiStrickand locus of control scale (Duke and Nowicki, 1973); Barnett et al.'s (1983) Life Events Score; an indicator variable that takes the value 1 if pregnancy was unplanned; an indicator variable that takes value 1 if the mother was in local authority care; an indicator variable that takes value 1 if she had divorced parents by age 17; an indicator variable that takes value 1 if the mother's main carer died by age 17;

\section{Appendix 2}

See Table 7.

Table 7 Socio-demographic characteristics of study population

\begin{tabular}{llrl}
\hline & Units & Mean & $\begin{array}{l}\text { (Std. } \\
\text { error })\end{array}$ \\
\hline Pregnancy and birth & & & \\
Gestation in weeks & Weeks & 39.47 & $(1.8)$ \\
Mother's age at birth & Years & 28.34 & $(4.8)$ \\
C-section & $0 / 1$ & 0.09 & $(0.3)$ \\
Primiparous & $0 / 1$ & 0.45 & $(0.5)$ \\
Mother works at 18 weeks & $0 / 1$ & 0.55 & $(0.5)$ \\
Cigarettes at 32 w & No. & 2.00 & $(5.1)$ \\
Previous alcohol consumption & No. & 2.59 & $(0.8)$ \\
Child characteristics at birth & & & \\
Female & $0 / 1$ & 0.49 & $(0.5)$ \\
Twin & $0 / 1$ & 0.01 & $(0.1)$ \\
Birth weight & grams & $3,419.93$ & $(543.9)$ \\
Head circumference & inches & 34.84 & $(1.4)$ \\
Crown-heel length & inches & 50.52 & $(2.2)$ \\
Demographic and socio-economic variables & & \\
White mother & $0 / 1$ & 0.95 & $(0.2)$ \\
Mother cohabiting & $0 / 1$ & 0.20 & $(0.4)$ \\
Mother single & $0 / 1$ & 0.04 & $(0.2)$ \\
Owner occupier & $0 / 1$ & 0.74 & $(0.4)$ \\
\hline
\end{tabular}


Table 7 continued

\begin{tabular}{|c|c|c|c|}
\hline & Units & Mean & $\begin{array}{l}\text { (Std. } \\
\text { error) }\end{array}$ \\
\hline Private rented & $0 / 1$ & 0.07 & $(0.3)$ \\
\hline Number of rooms & $0 / 1$ & 1.59 & $(0.9)$ \\
\hline Neighbourhood qual. & $0 / 1$ & 8.25 & $(2.2)$ \\
\hline \multicolumn{4}{|l|}{ Father's education } \\
\hline University degree & $0 / 1$ & 0.17 & $(0.4)$ \\
\hline $\begin{array}{l}\text { A level (academic qualifications } \\
\text { age 18) }\end{array}$ & $0 / 1$ & 0.25 & $(0.4)$ \\
\hline $\begin{array}{l}\text { O level (academic qualifications } \\
\text { age 16) }\end{array}$ & $0 / 1$ & 0.35 & $(0.5)$ \\
\hline CSE (lower-level academic quals) & $0 / 1$ & 0.15 & $(0.4)$ \\
\hline Vocational & $0 / 1$ & 0.08 & $(0.3)$ \\
\hline \multicolumn{4}{|l|}{ Mother's education } \\
\hline University degree & $0 / 1$ & 0.13 & $(0.3)$ \\
\hline $\begin{array}{l}\text { A level (academic qualifications } \\
\text { age 18) }\end{array}$ & $0 / 1$ & 0.22 & $(0.4)$ \\
\hline $\begin{array}{l}\text { O level (academic qualifications } \\
\text { age 16) }\end{array}$ & $0 / 1$ & 0.42 & $(0.5)$ \\
\hline CSE (lower-level academic quals) & $0 / 1$ & 0.14 & $(0.3)$ \\
\hline Vocational & $0 / 1$ & 0.10 & $(0.3)$ \\
\hline \multicolumn{4}{|l|}{ Breastfeeding attitudes } \\
\hline Mother was breastfed & $0 / 1$ & 0.48 & $(0.5)$ \\
\hline Father was breastfed & $0 / 1$ & 0.32 & $(0.5)$ \\
\hline Father breastfeeding attitudes & score & 15.39 & $(2.4)$ \\
\hline \multicolumn{4}{|l|}{ Mother's health in pregnancy } \\
\hline Mother health always well & $0 / 1$ & 0.29 & $(0.5)$ \\
\hline Mother health usually well & $0 / 1$ & 0.64 & $(0.5)$ \\
\hline Mother health sometimes unwell & $0 / 1$ & 0.06 & $(0.2)$ \\
\hline Mother health often unwell & $0 / 1$ & 0.01 & $(0.1)$ \\
\hline \multicolumn{4}{|c|}{ Interpersonal relationships and stressful life events } \\
\hline Mother's social network score & score & 23.34 & $(3.8)$ \\
\hline Mother's affection score & score & 11.17 & $(4.2)$ \\
\hline Mother's aggression score & score & 10.00 & $(1.7)$ \\
\hline Mother's std. locus/control score & score & 0.00 & $(1.1)$ \\
\hline Mother's life events score & score & 8.05 & (7.3) \\
\hline This pregnancy unplanned & $0 / 1$ & 0.28 & $(0.4)$ \\
\hline Mother in care & $0 / 1$ & 0.02 & $(0.2)$ \\
\hline Mother's parents divorced by 17 & $0 / 1$ & 0.15 & $(0.4)$ \\
\hline Mother's parents died by 17 & $0 / 1$ & 0.10 & $(0.3)$ \\
\hline
\end{tabular}

\section{References}

1. O'Hara, M., \& Swain, A. (1996). Rates and risk of postpartum depression: a meta-analysis. International Review of Psychiatry, $8(1), 37-54$.

2. Gavin, N. I., Gaynes, B. N., Lohr, K. N., Meltzer-Brody, S., Gartlehner, G., \& Swinson, T. (2005). Perinatal depression: A systematic review of prevalence and incidence. Obstetrics and Gynecology, 106, 1071-1083.
3. Horowitz, J. A., \& Goodman, J. (2004). A longitudinal study of maternal postpartum depression symptoms. Research and Theory for Nursing Practice, 18(2-3), 149-163.

4. Josefsson, A., \& Sydsjö, G. (2007). A follow-up study of postpartum depressed women: Recurrent maternal depressive symptoms and child behavior after four years. Archive of Women's Mental Health, 10(4), 141-145.

5. Pincus, H. A., \& Pettit, A. R. (2001). The societal costs of chronic major depression. Journal of Clinical Psychiatry, 62(6), 5-9.

6. Murray L., Halligan S.L., Cooper P.J. (2010) Effects of postnatal depression on mother-infant interactions, and child development. In: Wachs T., Bremner G., (Eds.) Vol. 192-220. Wiley-Blackwell. (Handbook of Infant Development).

7. Dennis, C.L., (2003) "Cost burden of postnatal depression significant in the UK", PharmacoEconomics and Outcomes News, 1(399): 7-7(1).

8. Knapp, M., McDaid, D., \& Parsonage, M. (Eds.). (2011). Mental health promotion and mental illness prevention: the economic case. London: Department of Health.

9. Kendall-Tackett, K., Cong, Z., \& Hale, T. W. (2011). The effect of feeding method on sleep duration, maternal well-being, and postpartum depression. Clinical Lactation, 2(2), 22-26.

10. Hatton, Daniel C. Jane Harrison-Hohner, MSN, Sarah Coste, $\mathrm{PhD}$, Veronica Dorato, RN, Luis B. Curet, MD, and David A. McCarron, MD.(2005) Symptoms of Postpartum Depression and Breastfeeding. Journal of Human Lactation, 21(4), 444-449.

11. Ystrom, E. (2012). Breastfeeding cessation and symptoms of anxiety and depression: a longitudinal cohort study. BMC Pregnancy and Childbirth, 12(1), 36.

12. Kendall-Tackett, K. (2007) A new paradigm for depression in new mothers: The central role of inflammation and how breastfeeding and anti-inflammatory treatments protect maternal mental health, International Breastfeeding Journal. doi:10.1186/17464358-2-6.

13. Mezzacappa, E. S., \& Katkin, E. S. (2002). Breast-feeding is associated with reductions in perceived stress and negative mood in mothers. Health Psychology, 21, 187-193.

14. McCoy, S. J. B., Beal, J. M., Shipman, S. B. M., Payton, M. E., \& Watson, G. H. (2006). Risk factors for postpartum depression: a retrospective investigation at 4-weeks postnatal and a review of the literature. JAOA: Journal of the American Osteopathic Association, 106(4), 193-198.

15. Alder, E. M., \& Cox, J. L. (1983). Breast feeding and post-natal depression. Journal of Psychosomatic Research, 27(2), 139-144.

16. Alder, E., \& Bancroft, J. (1988). The relationship between breast feeding persistence, sexuality and mood in postpartum women. Psychological Medicine, 18(2), 389-396.

17. Chung, E. K., McCollum, K. F., Elo, I. T., Lee, H. J., \& Culhane, J. F. (2004). Maternal depressive symptoms and infant health practices among low-income women. Pediatrics, 113, e523.

18. Dennis, C. L., \& McQueen, K. (2007). Does maternal postpartum depressive symptomatology influence infant feeding outcomes? Acta Paediatrica, 96(4), 590-594.

19. Reading, R., \& Reynolds, S. (2001). Debt, social disadvantage and maternal depression. Social Science and Medicine, 53, 441-453.

20. Dennis, C. L., \& McQueen, K. (2009). The relationship between infant-feeding outcomes and postpartum depression: a qualitative systematic review. Pediatrics, 123, e736.

21. Fairlie, T. G., Gillman, M. W., \& Rich-Edwards, J. (2009). High pregnancy-related anxiety and prenatal depressive symptoms as predictors of intention to breastfeed and breastfeeding initiation. Journal of Women's Health, 18(7), 945.

22. Henderson, J. J., Evans, S. F., \& Straton, J. A. (2003). Impact of postnatal depression on breastfeeding duration. Birth, 30(3), $175-180$. 
23. Seimyr, L., Edhborg, M., \& Lundh, W. (2004). In the shadow of maternal depressed mood: experiences of parenthood during the first year after childbirth. Journal of Psychosomatic Obstetrics and Gynecology, 25(1), 23-34.

24. Ip, S., Chung, M., Raman, G., Chew, P., Magula, N., DeVine, D., et al. (2007). Breastfeeding and maternal and infant health outcomes in developed countries. Evid Rep Technology Assess (Full Rep), 153, 1-186.

25. Groër, M. W. (2005). Differences between exclusive breastfeeders, formula-feeders, and controls: a study of stress, mood, and endocrine variables. Biological Research for Nursing, 7(2), 106-117.

26. Golding, J., Pembrey, M., Jones, R., \& and the ALSPAC Study Team. (2001). ALSPAC-The Avon longitudinal study of parents and children. Paediatric and Perinatal Epidemiology, 15, 74-87.

27. ALSPAC data dictionary, available online at: http://www.bris.ac. uk/alspac/researchers/data-access/data-dictionary/.

28. Cox, J. L., Holden, J. M., \& Sagovsky, R. (1987). Detection of postnatal depression: Development of the 10-item Edinburgh depression scale. British Journal of Psychiatry, 150, 782-788.

29. Horowitz, J. A., \& Goodman, J. (2004). A longitudinal study of maternal postpartum depression symptoms. Research and Theory for Nursing Practice, 18(2-3), 149-163.

30. Matthey, S., Henshaw, C., Elliott, S., \& Barnett, B. (2006). Variability in use of cut-off scores and formats on the Edinburgh Postnatal Depression Scale: implications for clinical and research practice. Archives of Women's Mental Health, 9(6), 309-315.

31. Cox, J. L., Holden, J. M., \& Sagovsky, R. (1987). Detection of postnatal depression: Development of the 10-item Edinburgh depression scale. British Journal of Psychiatry, 150, 782-788.
32. Murray, L., \& Cox, J. L. (1990). Screening for depression during pregnancy with the Edinburgh Depression Scale (EPDS). Journal of Reproductive and Infant Psychology, 8, 99-107.

33. Choi, S. K., Kim, J. J., Park, Y. G., Ko, H. S., Park, I. Y., \& Shin, J. C. (2012). The simplified edinburgh postnatal depression scale (EPDS) for antenatal depression: Is it a valid measure for prescreening? International Journal of Medical Sciences, 9(1), $40-46$.

34. O’Hara, M., \& Swain, A. (1996). Rates and risk of postpartum depression: a meta-analysis. International Review of Psychiatry, 8(1), 37-54.

35. Muriel, J. "Creating an enhanced service will improve care in depression" Guidelines in Practice, October 2004, Volume 7(10). http://www.eguidelines.co.uk/eguidelinesmain/gip/vol_7/oct_04/ murie_depression_oct04.htm\#refs.

36. Mezzacappa, E. S., \& Endicott, J. (2007). Parity mediates the association between infant feeding method and maternal depressive symptoms in the postpartum. Archives of Women's Mental Health, 10(6), 259-266.

37. Hatton, Daniel C. Jane Harrison-Hohner, MSN, Sarah Coste, $\mathrm{PhD}$, Veronica Dorato, RN, Luis B. Curet, MD, and David A. McCarron, MD. (2005) Symptoms of Postpartum Depression and Breastfeeding. Journal of Human Lactation, 21(4), 444-449.

38. Moehler, E., Brunner, R., Wiebel, A., Reck, C., \& Resch, F. (2006). Maternal depressive symptoms in the postnatal period are associated with long-term impairment of mother-child bonding. Archives of Women's Mental Health, 9(5), 273-278. 